Article

\title{
Experimental Investigation on the Deformation Behavior of Inconel 625 Superalloy at High Temperatures
}

\author{
Gyeong Uk Jeong ${ }^{1}$, Chul Kyu Jin ${ }^{2} \oplus$, Hyung Yoon Seo ${ }^{3}$ and Chung Gil Kang ${ }^{4, *}$ \\ 1 Precision Manufacturing System Division, Graduate School, Pusan National University, San 30 Chang \\ Jun-dong, Geum Jung-Gu, Busan 46241, Korea \\ 2 School of Mechanical Engineering, Kyungnam University, 7 Kyungnamdaehak-ro, Masanhappo-gu, \\ Changwon-si, Gyeongsangnam-do 51767, Korea \\ 3 Department of Computer Software Engineering, ChangShin University, 262 Paryong-ro, Masanhoiwon-gu, \\ Changwon-si, Gyeongsangnam-do 51352, Korea \\ 4 School of Mechanical Engineering, Pusan National University, San 30 Chang Jun-dong, Geum Jung-Gu, \\ Busan 46241, Korea \\ * Correspondence: cgkang@pusan.ac.kr; Tel.: +82-51-510-1455
}

Received: 2 May 2019; Accepted: 24 June 2019; Published: 26 June 2019

\begin{abstract}
Inconel 625 alloys are widely applied for high-corrosion resistance and as high-efficiency materials in aeronautical, aerospace, chemical, nuclear, petrochemical, and marine industries. Although Inconel 625 alloys are excellent materials, they cannot be formed at room temperature owing to difficulties in processing. To improve the formability of Inconel 625, it is necessary to investigate its formability at a high-temperature range and its strain rate variation. In this study, high-temperature deformation behavior after forming was investigated. A high-temperature compression test was performed with a Gleeble 3500 testing machine at various temperatures (approximately $900-1200{ }^{\circ} \mathrm{C}$ ) and strain rates $\left(10\right.$ and $\left.30 \mathrm{~s}^{-1}\right)$ to obtain the high-temperature deformation characteristics of Inconel 625. Furthermore, high-temperature tensile tests were performed to measure elongations and reductions in the area of the Inconel 625 alloy. The tests focused on obtaining the flow stress data and optimal hot forging conditions under various strain rates and temperatures. The results of this research are expected to contribute to hot forming processes and to formability in hot extrusion and pilger processes.
\end{abstract}

Keywords: Inconel 625; seamless tube; high-temperature compression test; high-temperature tension test; microstructures

\section{Introduction}

The demand for offshore plants in the shipbuilding and offshore industries has increased sharply. Consequently, the demand for nickel alloy seamless tubes, which have high environmental resistance, has increased. Seamless tubes are applied in harsh corrosive environments and require high-temperature mechanical characteristics in marine and chemical plants for the mining of energy sources such as petroleum, natural gas, and military supplies [1]. Lately, the demand for petroleum pipelines in offshore plants has been increasing. However, the seamless tubes used as oil transfer tubes are mostly produced from billet by a hot forging process because of the difficulty of forming rigid workable materials using cold working methods. The existing manufacturing process for high-corrosion-resistant nickel base superalloy seamless pipes, such as Inconel 625 and Inconel 718, involves a boring process where holes are processed in the center of the billet to make a preform shape, and high-corrosion-resistant pipe is produced by hot extrusion and the pilger process using the preform. However, this process causes 
damage to the boring tool, the frequent replacement of which results in increased overall production costs in the boring process. Furthermore, due to the lack of data on the high-temperature deformation characteristics of the seamless tube, it is difficult to analyze the cause of cracks during hot forging and to set optimal conditions for hot forging [2].

Recently, a method for manufacturing an Inconel 625 seamless tube with desired dimensions from a circular cross-section pipe manufactured by centrifugal casting was studied in order to reduce the production costs of the material and to improve the formability. Basic study of the microstructure, mechanical properties, and the forming limit of the seamless tube according to changes in the forging condition when the seamless tube is formed by applying forging after centrifugal casting is needed. Altan [3] predicted the optimal hot forging conditions by investigating the effects of temperature and strain rate on stress flow, as these are process parameters of the hot forging of metal. He proposed flow stress data for metallic materials such as aluminum, copper, and titanium alloy.

Rao [4] proposed an algorithm to determine the flow stress under various process conditions. He also developed a high-temperature compression test method by conducting a hot deformation test for low-carbon steel as well as medium-carbon steel. Guo [5] investigated the high-temperature softening characteristics of dynamic recrystallization and dynamic recovery during high-temperature deformation and proposed optimal hot forging conditions. In addition, Lee [6] and Zouari [7] proposed a process method for lowering the strain resistance of SPF8090 Al-Li and for the grain refinement of Inconel 718. Bang [8] and Cho [9] offered a method to predict the forming load and microstructure during the high-temperature deformation of carbon steel. However, research on the prediction of the forming load and microstructural details during high-temperature deformation utilizing a finite element method has not been published yet.

In this study, a basic investigation of Inconel 625 is performed using cylindrical preform manufactured by the centrifugal casting process for the application of the seamless tube. To investigate the deformation characteristics at high temperature, compression tests (under 900, 1000, 1100, and $1200^{\circ} \mathrm{C}$ ) and tensile tests (under $900,1000,1100$, and $1200^{\circ} \mathrm{C}$ ) are conducted.

\section{Experiments}

\subsection{Compression Test at High Temperature}

A compression test is a useful method to understand the formability of a material. A high-temperature compression test was performed in this study to determine the flow stress of the material under a high temperature. The testing device used in this high-temperature compression test corresponded to the Gleeble 3500 (Dynamic Systems Inc, New York, NY, USA), which is mainly used for tensile and compression tests conducted at high temperatures. The material used in the study corresponded to Inconel 625 for the seamless tube. The Inconel 625 under investigation has the following chemical composition (wt. $\%$ ): $0.001 \% \mathrm{Si}, 0.010 \% \mathrm{Mg}, 0.050 \% \mathrm{C}, 0.050 \% \mathrm{Mn}, 0.160 \% \mathrm{Ti}, 0.180 \%$ $\mathrm{Al}, 3.730 \% \mathrm{Nb}, 3.780 \% \mathrm{Fe}, 8.660 \% \mathrm{Mo}, 22.040 \% \mathrm{Cr}$, and $61.240 \% \mathrm{Ni}$.

A cylindrical specimen with a diameter of $8 \mathrm{~mm}$, height of $12 \mathrm{~mm}$, and ratio of diameter to height of 1.5 was fabricated. A thin tantalum foil was used to prevent fusion between the specimen and mold during the experiment. Additionally, thermocouples were attached to the center of the specimens by using a spot-welding method to measure and control the temperature. Testing was performed when a test specimen was heated at a heating rate of $50{ }^{\circ} \mathrm{C} / \mathrm{s}$ by employing the current resistance heating method. The temperature of the entire specimen was maintained for $3 \mathrm{~min}$ after it was stabilized. The compression test was performed to reduce the height to $70 \%$ (height of $3.6 \mathrm{~mm}$ ), and this was followed by immediate air-cooling while maintaining the target temperature for $3 \mathrm{~min}$. The test was performed at temperatures of $900,1000,1100$, and $1200^{\circ} \mathrm{C}$, and strain rates of 10 and $30 \mathrm{~s}^{-1}$. 


\subsection{Tensile Test at High Temperature}

The tensile test is a useful testing method for investigating the mechanical properties of a material. However, under high temperatures, materials continue to recrystallize, and this sharply deteriorates strain hardening. This explains why necking occurs at the initial stage of the tensile test and why it is not useful to obtain flow stress from the information prior to the occurrence of necking. Furthermore, it is not easy to obtain flow stress from the tensile test results, owing to the high strain rate and the dependency of the strain rate, even after necking. Generally, a high-temperature tensile test is an extremely useful tool to evaluate the formability of the materials under high temperatures, and it is mainly used to determine the elongation rate and reduction rate in the cross-section of the material. The equipment for the high-temperature tensile test is Gleeble 3500. The diameter and length of specimen is $10 \mathrm{~mm}$ and $116.5 \mathrm{~mm}$, respectively. The testing procedure was identical to that used in the high-temperature compression test. The high-temperature tensile test was performed with variable strain rates $\left(0.1,10\right.$, and $\left.30 \mathrm{~s}^{-1}\right)$ and temperatures $\left(900,1000,1100\right.$, and $\left.1200{ }^{\circ} \mathrm{C}\right)$.

\subsection{Analysis Method}

The graphs of true stress versus strain rate were created using Equation (1):

$$
\sigma=C \dot{\varepsilon}^{m}
$$

Here, $\sigma$ is the true stress, $C$ is the strength coefficient, $\dot{\varepsilon}$ is the strain rate, and $m$ is the strain rate sensitivity index.

This curve-fitting method aims to calculate a strength coefficient and strain rate sensitivity index by applying curve-fitting after arranging the flow stress based on the strain rate at each true strain, which corresponds to $0.1,0.3,0.5$, and 0.7 when the temperature is constant. The strength coefficient and the strain rate sensitivity index were obtained from the stress-strain curves of the compression tests at different temperatures and strain rates.

The microstructure of the specimen was examined after etching based on ASTM E407-07(2015)e1, in order to observe structural changes in the specimen. An optical microscope was used to monitor the microstructure. The reduction in area is the degree of plastic deformation of material in a high-temperature tensile test. The reduction in area is defined as Equation (2):

$$
\mathrm{A}_{\mathrm{s}}=\frac{\mathrm{A}_{\mathrm{o}}-\mathrm{A}_{\mathrm{f}}}{\mathrm{A}_{\mathrm{o}}} \times 100(\%)
$$

Here, $A_{s}$ is the section reduction rate, $A_{0}$ is the initial cross-sectional area, and $A_{f}$ is the cross-sectional area at the fracture site.

\section{Results}

\subsection{Compression Test at High Temperature}

The true stress-true strain curves of the compression tests at different temperatures $\left(900-1200{ }^{\circ} \mathrm{C}\right)$ and strain rates $\left(10\right.$ and $\left.30 \mathrm{~s}^{-1}\right)$ are shown in Figure 1. An increase in temperature at a constant strain rate decreases the flow stress. An increase in the strain rate at a constant temperature increases the flow stress. The shape of the stress-strain curve exhibits a steady state in which the flow stress increases when the strain increases until the maximum stress is observed, and then the flow stress gradually decreases until no further stress reduction is observed after a constant strain. It has been reported that active dynamic recrystallization becomes a major strain mechanism at strain temperatures exceeding $1000^{\circ} \mathrm{C}$, and this reduces the gradient of the strain curve [10]. 


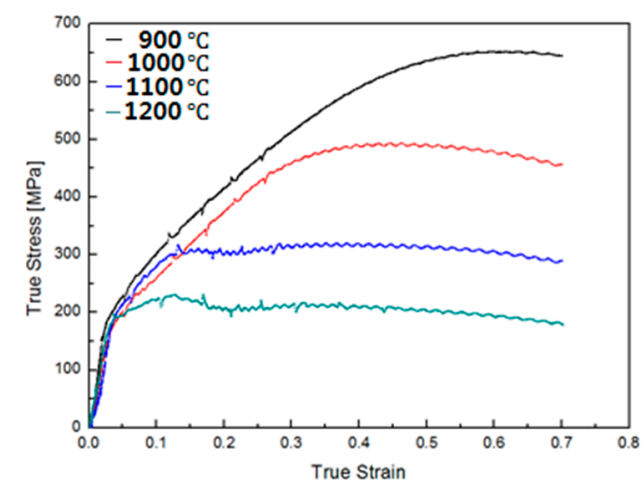

(a)

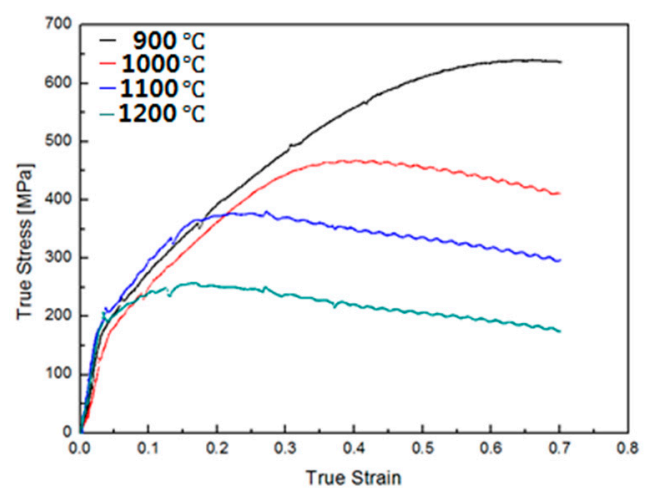

(b)

Figure 1. True stress-true strain curves of the compression tests at different temperatures and strain rates: (a) strain rate $10 \mathrm{~s}^{-1},(\mathbf{b})$ strain rate $30 \mathrm{~s}^{-1}$.

Guo et al. [5] showed the true stress based on changes in the true strain, under a strain rate of $0.1 \mathrm{~s}^{-1}$ and with temperatures ranging from 900 to $1200^{\circ} \mathrm{C}$. An increase in the strain rate in each temperature zone clearly increased flow stress.

The graphs of true stress versus strain rate at different temperatures and at true strain are shown in Figure 2. The data shown in the graph corresponds to the strain rates of $10 \mathrm{~s}^{-1}$ and $30 \mathrm{~s}^{-1}$ used in our experiments and the strain rate of $0.1 \mathrm{~s}^{-1}$ used by Guo et al. [5]. The strength coefficient and strain rate sensitivity values presented by the curve-fitting method are shown in Table 1 . The data in our experiment and the data presented by Guo et al. [5] were used to obtain the strength coefficient and strain rate sensitivity. An increase in the temperature was shown to decrease the strain rate strength coefficient. Additionally, the strain rate sensitivity exhibited an increasing tendency. Specifically, the high $\mathrm{m}$ value at a high temperature indicates that an increase in the process temperature increases the benefits of generating the strain. An increase in the plasticity strain increases the $m$ value, and this implies that the strain occurrence becomes easier, owing to changes in the internal microstructure during strain [10]. As shown in Figure 2, with respect to the 900 and $1000^{\circ} \mathrm{C}$ curves at a true strain rate of $0.1 \mathrm{~s}^{-1}$ and the $900^{\circ} \mathrm{C}$ curve at the true strain rate of 0.3 , the strain rate sensitivity index $\mathrm{m}$ is below 0 . This value is different in terms of the gradient from the $\mathrm{m}$ value that exceeds 0 with respect to the curves at 1100 and $1200{ }^{\circ} \mathrm{C}$. The $\mathrm{m}$ value was reported to be positive for most of the alloys. However, if the $\mathrm{m}$ value becomes negative, there is a possibility of crack generation on the surface of the forging part [11]. It was confirmed that the $\mathrm{m}$ value was negative at 900 and $1000{ }^{\circ} \mathrm{C}$, and positive at 1100 and $1200^{\circ} \mathrm{C}$ during the hot forging of Inconel 625 alloy, thus, cracks could occur at 900 and $1000{ }^{\circ} \mathrm{C}$.

Table 1. Values of the strength coefficient $(C)$ and strain rate sensitivity $(m)$ at different temperatures and true strains.

\begin{tabular}{ccccccccc}
\hline \multirow{2}{*}{$\begin{array}{c}\text { True } \\
\text { Strain }\end{array}$} & \multicolumn{2}{c}{$\mathbf{9 0 0}{ }^{\circ} \mathbf{C}$} & \multicolumn{2}{c}{$\mathbf{1 0 0 0}{ }^{\circ} \mathbf{C}$} & \multicolumn{2}{c}{$\mathbf{1 1 0 0}{ }^{\circ} \mathbf{C}$} & \multicolumn{2}{c}{$\mathbf{1 2 0 0}{ }^{\circ} \mathbf{C}$} \\
\cline { 2 - 9 } & $\boldsymbol{C} \mathbf{( M P a )}$ & $\boldsymbol{m}$ & $\boldsymbol{C} \mathbf{( M P a )}$ & $\boldsymbol{m}$ & $\boldsymbol{C} \mathbf{( M P a )}$ & $\boldsymbol{m}$ & $\boldsymbol{C} \mathbf{( M P a )}$ & $\boldsymbol{m}$ \\
\hline 0.1 & 349 & -0.05 & 294 & -0.04 & 242 & 0.07 & 164 & 0.13 \\
0.3 & 584 & -0.05 & 395 & 0.05 & 247 & 0.12 & 140 & 0.17 \\
0.5 & 674 & -0.02 & 379 & 0.08 & 232 & 0.12 & 129 & 0.17 \\
0.7 & 673 & -0.01 & 342 & 0.08 & 204 & 0.13 & 113 & 0.16 \\
\hline
\end{tabular}




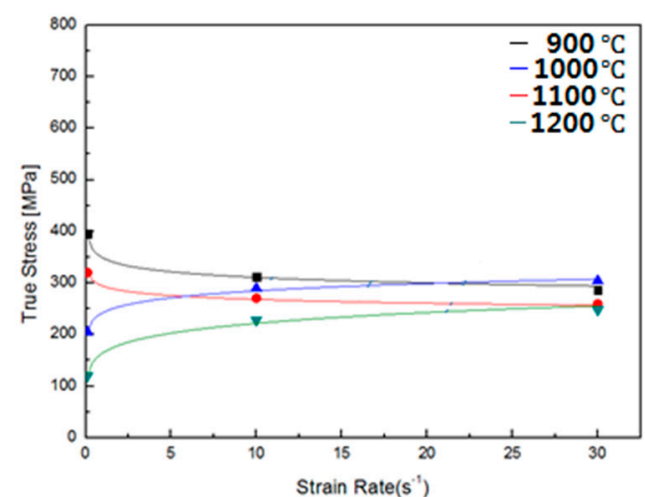

(a)

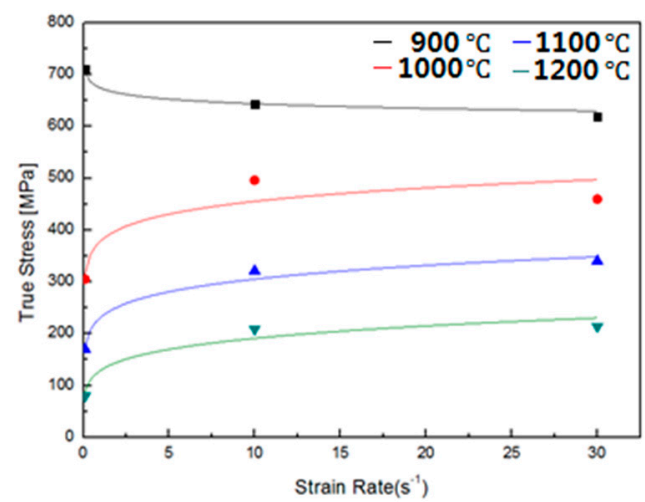

(c)

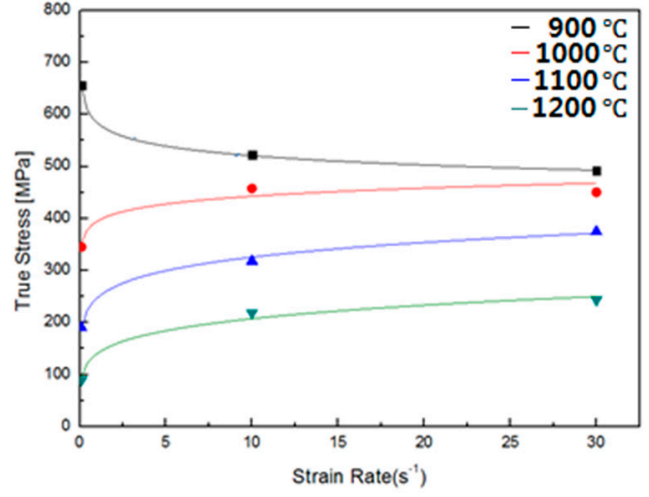

(b)

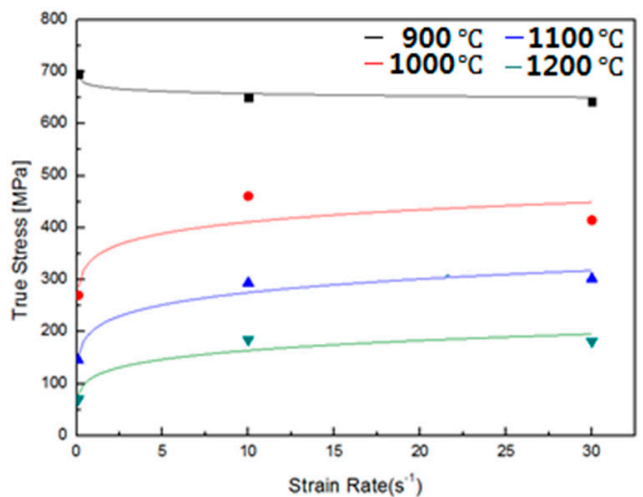

(d)

Figure 2. Graph of true stress versus strain rate at different temperatures and true strains: (a) true strain $0.1,(\mathbf{b})$ true strain $0.3,(\mathbf{c})$ true strain $0.5,(\mathbf{d})$ true strain 0.7.

The shapes of test specimens after the high-temperature compression test are shown in Figure 3. The specimens were exposed to a compression rate of $70 \%$ under constant strain rates $\left(10 \mathrm{~s}^{-1}\right.$ and $30 \mathrm{~s}^{-1}$ ) at each temperature $\left(900-1200^{\circ} \mathrm{C}\right)$. The friction force was imposed at the contact area of the die and specimen towards the opposite direction of the flow, which caused barreling. No cracks were observed in any of the eight conditions tested.

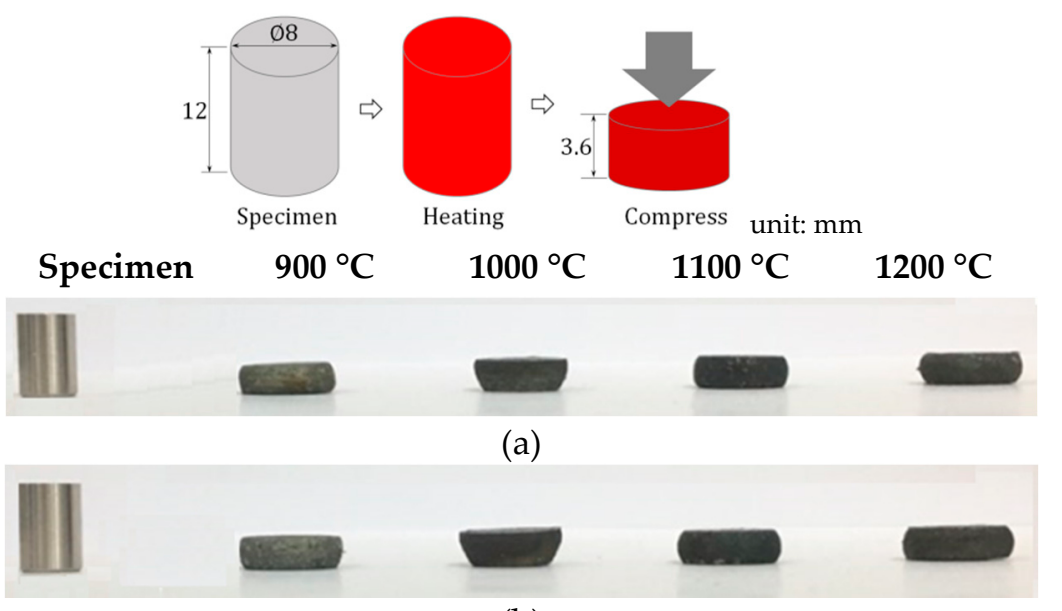

(b)

Figure 3. Shapes of specimens after high-temperature compression: (a) $10 \mathrm{~s}^{-1}$ strain rate, (b) $30 \mathrm{~s}^{-1}$ strain rate. 
The microstructures of the specimens at different temperatures are shown in Figure 4. It was confirmed that the microstructure in (Top) exhibited a narrow grain boundary when compared with (Center) and (Edge) due to the load imposed on the specimen. Additionally, at $1200{ }^{\circ} \mathrm{C}$, the grain boundary was blurred in contrast to the compression test specimens at different temperatures. It was found that the strain rate aids in grain refinement when the temperature is lower than $1100{ }^{\circ} \mathrm{C}$, while the effect of the strain rate is reduced when the strain temperature exceeds $1100{ }^{\circ} \mathrm{C}$ [12].

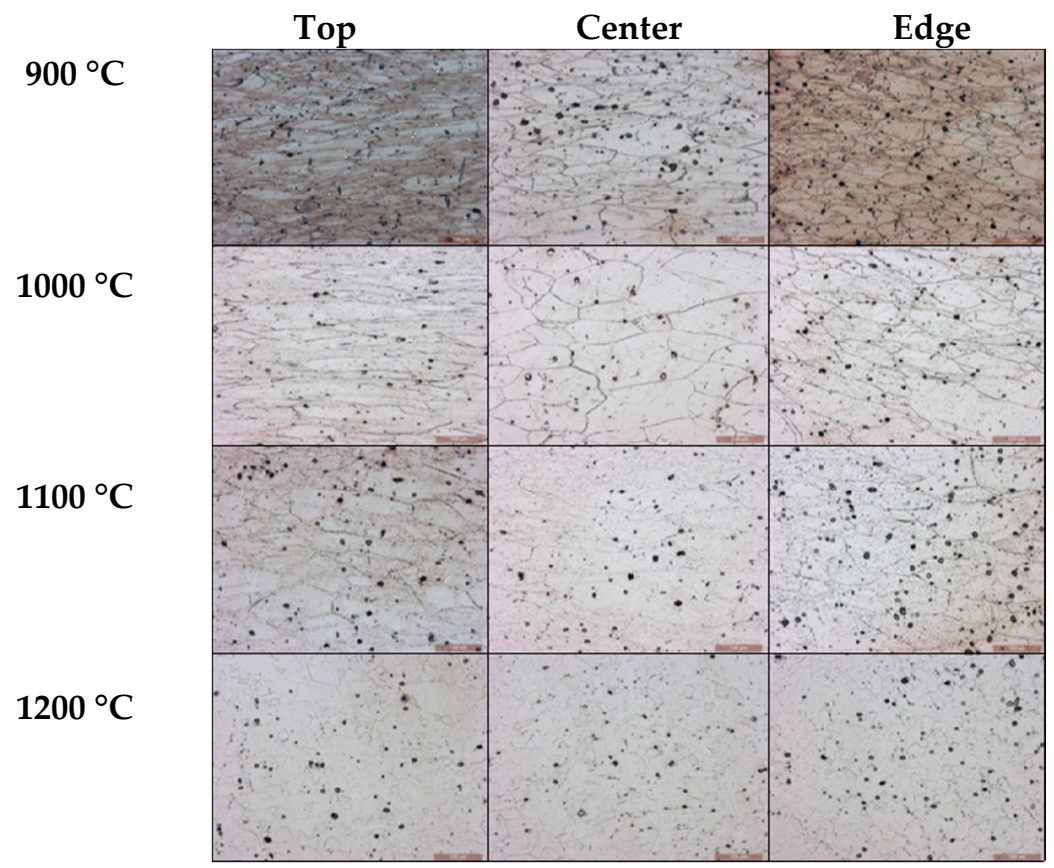

Figure 4. Microstructures of Inconel 625 specimens after the compression test according to the temperature.

\subsection{Tensile Test at High Temperature}

The true stress-true strain curves obtained by tensile tests at different temperatures and strain rates are shown in Figure 5. An increase in the temperature reduced the flow stress. Furthermore, the flow stress increased when the strain rate increased. 


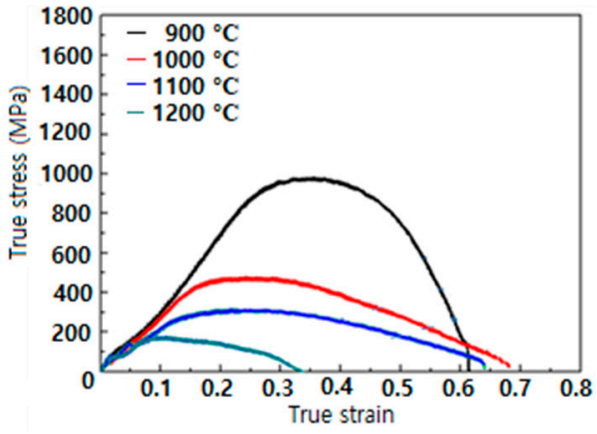

(a)

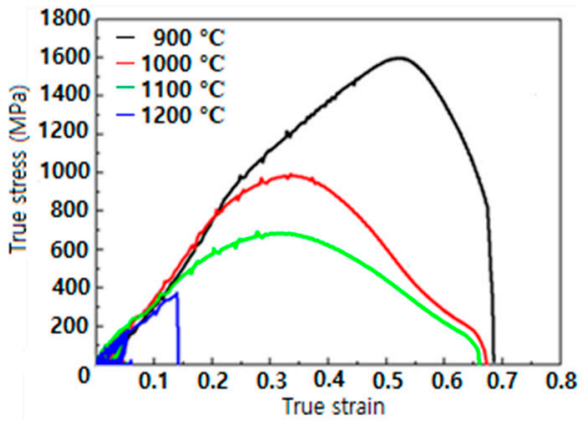

(b)

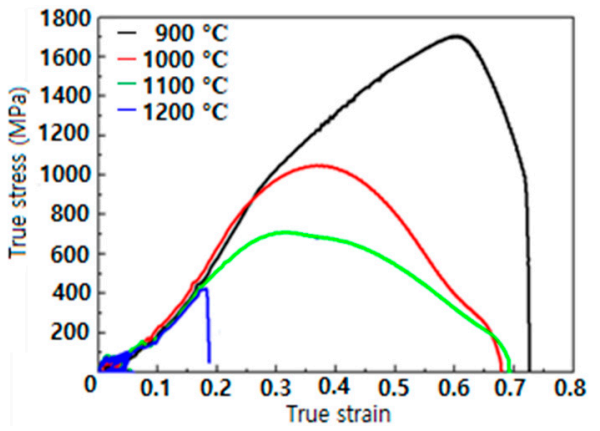

(c)

Figure 5. True stress-true strain curve obtained by tensile tests at different temperatures and strain rates: (a) $0.1 \mathrm{~s}^{-1}$ strain rate, (b) $10 \mathrm{~s}^{-1}$ strain rate, (c) $30 \mathrm{~s}^{-1}$ strain rate

The profile of the stress-strain curve shows an increase in the strain-magnified flow stress, with the specimen fractured after exhibiting the maximum stress.

The fractured shapes of the specimens exposed to the high-temperature tensile test are shown in Figure 6. The changes in specimens were based on changes in the temperature $\left(1100\right.$ and $\left.1200{ }^{\circ} \mathrm{C}\right)$ at a constant strain rate $\left(0.1,10\right.$, and $\left.30 \mathrm{~s}^{-1}\right)$. A ductile fracture occurred in the specimens tested at 900,1000 , and $1100^{\circ} \mathrm{C}$, regardless of the strain rate. Meanwhile, a brittle fracture was observed in the specimen at $1200^{\circ} \mathrm{C}$ (photos of specimens tested at 900 and $1000^{\circ} \mathrm{C}$ are not shown).

$1100{ }^{\circ} \mathrm{C}$

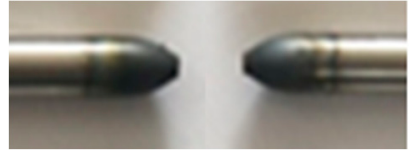

(a)

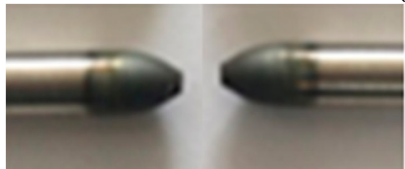

(b)

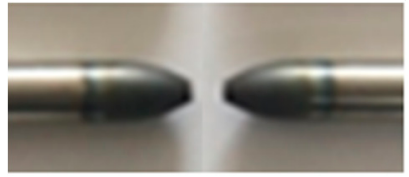

(c)
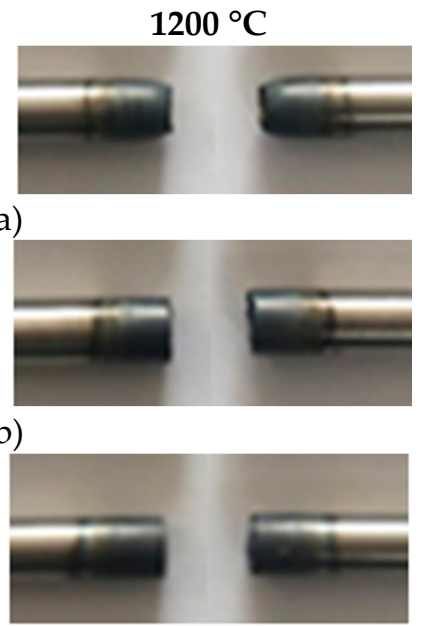

Figure 6. Fractured shapes of the tensile test specimens at 1100 and $1200{ }^{\circ} \mathrm{C}$ : (a) $0.1 \mathrm{~s}^{-1}$ strain rate, (b) $10 \mathrm{~s}^{-1}$ strain rate, (c) $30 \mathrm{~s}^{-1}$ strain rate. 
The changes in the section reduction rate of a specimen area according to strain rate and temperature are shown in Figure 7. When the temperature was increased from 900 to $1000{ }^{\circ} \mathrm{C}$, the section reduction rate also increased. However, if the temperature was further increased from 1100 to $1200{ }^{\circ} \mathrm{C}$, the section reduction rate decreased. The section reduction rate was a little higher at 1100 ${ }^{\circ} \mathrm{C}$ than at $900{ }^{\circ} \mathrm{C}$. When the temperature increased from 1100 to $1200{ }^{\circ} \mathrm{C}$, the section reduction rate remarkably decreased. At $1200^{\circ} \mathrm{C}$, under the conditions of the deformations at $10 \mathrm{~s}^{-1}$ and $30 \mathrm{~s}^{-1}$, the section reduction rate was almost zero, and a complete brittle fracture occurred. In general, as the deformation speed became lower, the section reduction rate tended to increase. An increase in the temperature abruptly decreased the section reduction rate at a certain temperature $\left(1200{ }^{\circ} \mathrm{C}\right)$. The reason why the section reduction rate sharply decreased at $1200{ }^{\circ} \mathrm{C}$ was hot shortness [13]. It was found that there is a ductile to brittle transition temperature (DBTT) between 1100 and $1200{ }^{\circ} \mathrm{C}$ at which a material's characteristics change from ductile to brittle.

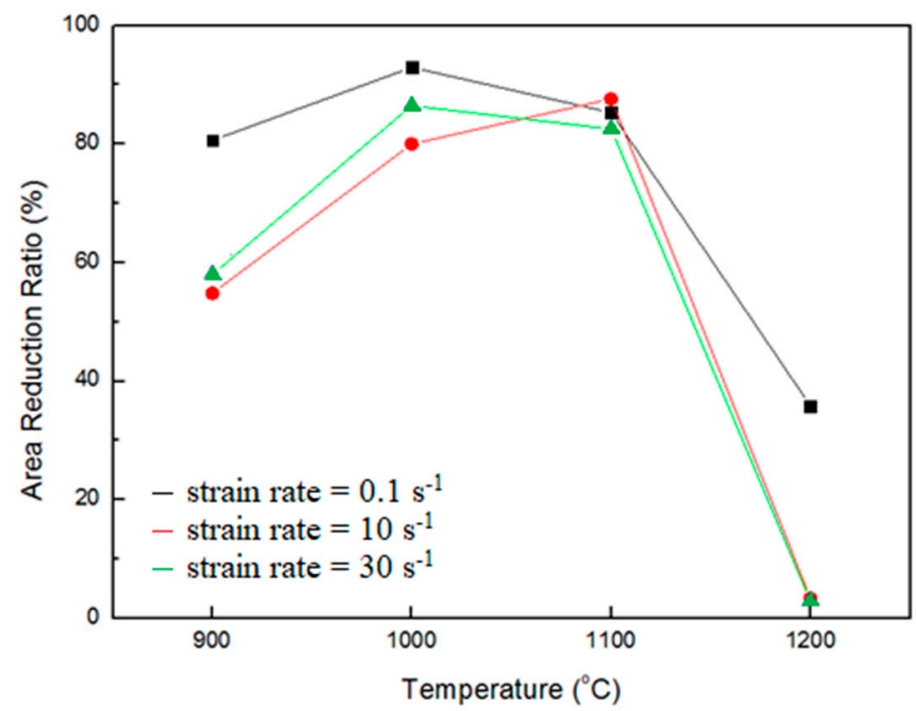

Figure 7. Reduction in the area of the tensile test specimen at different temperatures and strain rates.

\section{Conclusions}

High-temperature compression and tensile tests were conducted to obtain the high-temperature plastic strain characteristics of Inconel 625 alloy at various temperatures $\left(900-1200{ }^{\circ} \mathrm{C}\right)$ and strain rates (10 and $\left.30 \mathrm{~s}^{-1}\right)$. The following conclusions were obtained:

(1) In the high-temperature compression test for the Inconel 625 alloy, the test results confirmed that the strength coefficient decreased when temperature increased while the strain rate sensitivity index exhibited an increasing tendency.

(2) The Inconel 625 alloy exhibited cracks on its surface during hot forging at $900-1000{ }^{\circ} \mathrm{C}$ because the strain rate sensitivity index displayed a negative value at $900-1000{ }^{\circ} \mathrm{C}$.

(3) An increase in the temperature reduced the flow stress, and the flow stress increased when the strain rate increased.

(4) The changes in the section reduction rate of Inconel 625 alloy in the high-temperature tensile test were confirmed upon performing the experiment. An increase in the temperature abruptly decreased the section reduction rate at a specific temperature $\left(1200^{\circ} \mathrm{C}\right)$.

(5) The cracks during the hot forging process could be attributed to the temperature. The optimum temperature condition of Inconel 625 alloy for hot forging is about $1100^{\circ} \mathrm{C}$.

Author Contributions: G.U.J. and C.K.J. designed the experiment tools and performed the experiment. C.K.J. and H.Y.S. analyzed the experimental results, whereas C.G.K. maintained and examined them. All authors have contributed to the discussions, as well as revisions. 
Funding: This work was supported by the National Research Foundation of Korea (NRF) grant funded by the Korean Government (MSIP) through the GCRC-SOP (No. 2011-0030013). This work was also supported by the National Research Foundation of Korea (NRF) grant funded by the Korean Government (MSIT) (No.2017R1A2B4007884), along with the National Research Foundation of Korea grant funded by the Korean Government (NRF-2017R1C1B5017242).

Conflicts of Interest: The authors declare no conflict of interest.

\section{References}

1. Guo, Q.M.; Li, D.F.; Guo, S.L. Microstructural Models of Dynamic Recrystallization in Hot-Deformed Inconel 625 Superalloy. Mater Manuf Process. 2012, 27, 990-995. [CrossRef]

2. Moon, H.K.; Lee, J.S.; Yoo, S.J.; Joun, M.S.; Lee, K.J. Hot Deformation Behavior of Bearing Steels. J. Eng. Mater. Technol. 2007, 129, 349-355. [CrossRef]

3. Altan, T.; Boulger, F.W. Flow Stress of Metals and its Application in Metal Forming Analyses. J. Eng. Ind. 1973, 95, 1009-1019. [CrossRef]

4. Rao, K.P.; Hawbolt, E.B. Development of Constitutive Relationships Using Compression Testing of a Medium Carbon Steel. J. Eng. Mater. Technol. 1992, 114, 116-123. [CrossRef]

5. Guo, Q.M.; Li, D.F.; Guo, S.L.; Peng, H.; Hu, J. The effect of deformation temperature on the microstructure evolution of Inconel 625 superalloy. J Nucl Mater. 2011, 414, 440-450. [CrossRef]

6. Chen, T.R.; Huang, J.C.; Liauo, J.M.; Hwang, Y.M. Effect of lubrication on superplastic forming of 8090 Al-Li sheets. Scr Metall Mater. 1994, 31, 309-314. [CrossRef]

7. Zouari, M.; Loge, R.E.; Bozzolo, N. In Situ Characterization of Inconel 718 Post-Dynamic recrystallization within a Scanning Electron Microscope. Metals 2017, 7, 476. [CrossRef]

8. Bang, W.; Lee, C.S.; Chang, Y.W. Finite element analysis of hot forging with flow softening by dynamic recrystallization. J. Mater. Process. Technol. 2003, 134, 153-158. [CrossRef]

9. Cho, J.R.; Jeong, H.S.; Cha, D.J.; Bae, Y.B.; Lee, J.W. Prediction of microstructural evolution and recrystallization behaviors of a hot working die steel by FEM. J. Mater. Process. Technol. 2005, 160, 1-8. [CrossRef]

10. Dhua, S.K.; Mukerjee, D.; Sarma, D.S. Influence of thermomechanical treatments on the microstructure and mechanical properties of HSLA-100 Steel Plates. Metall. Mater. Trans. A 2003, 34, 241-253. [CrossRef]

11. Ozturk, F.; Pekel, H.; Halkaci, H.S. The Effect of Strain-Rate Sensitivity on Formability of AA 5754-0 at Cold and Warm Temperatures. J. Mater. Eng. Perform. 2011, 20, 77-81. [CrossRef]

12. Guo, S.L.; Li, D.F.; Guo, Q.M.; Wu, Z.G.; Peng, H.; Hu, J. Investigation on hot workability characteristics of Inconel 625 superalloy using processing maps. J. Mater. Sci. 2012, 47, 5867-5878. [CrossRef]

13. Kwak, J.H.; Chung, J.H.; Cho, K.M. A strudy on the edge cracking of low carbon steel sheets manufactured by mini-mill process. In Proceedings of the 42nd Mechanical Working and Steel Processing Conference Proceedings, Toronto, ON, Canada, 22-25 October 2000.

(C) 2019 by the authors. Licensee MDPI, Basel, Switzerland. This article is an open access article distributed under the terms and conditions of the Creative Commons Attribution (CC BY) license (http://creativecommons.org/licenses/by/4.0/). 